\title{
Lung ultrasound for the diagnosis of childhood pneumonia: a safe and accurate imaging mode
}

This article was published in the following Dove Press journal:

Therapeutics and Clinical Risk Management

9 December 2015

Number of times this article has been viewed

\author{
Mohamed Ata Hendaus 1,2 \\ Fatima Ahmed Jomha ${ }^{3}$ \\ Ahmed Hassan Alhammadi ${ }^{1,2}$ \\ 'Department of Pediatrics, Academic \\ General Pediatrics Division, Hamad \\ Medical Corporation, Doha, \\ ${ }^{2}$ Weill Cornell Medical College-Qatar, \\ Al Rayyan, Qatar; ${ }^{3}$ School of Pharmacy, \\ Lebanese International University, \\ Khiara, Lebanon
}

\begin{abstract}
Pneumonia is the most common infectious cause of mortality in children worldwide. Chest X-ray (CXR) has been used as a supplementary mode in the diagnosis of pneumonia in children, but its frequent use might expose children to unnecessary ionizing radiation. In this review, we present up-to-date data of an alternative mode of imaging other than CXR in the diagnosis of pneumonia in children. We found that lung ultrasound is a safe and accurate mode of imaging that can be used by a health care provider in the cases of suspected pneumonia. It is more sensitive than CXR in the diagnosis of pneumonia and obviates the need for irradiation.
\end{abstract}

Keywords: lung ultrasound, children, pneumonia

\section{Introduction}

Pneumonia is the most common infectious cause of mortality in children worldwide. The World Health Organization predicts that pneumonia has a universal annual incidence of almost one million mortality cases in children, comprising approximately $15 \%$ of all deaths of individuals under 5 years of age. ${ }^{1}$ Despite the introduction of the pneumococcal conjugate vaccine, community-acquired pneumonia is still considered as a common cause of morbidity among children aged $\leq 5$ years in developed countries, where the incidence reaches from 10-40 cases per 1,000 subjects. ${ }^{2}$ The presentation of pneumonia in children varies according to the child's age group and the culprit microorganism, creating a diagnostic challenge among clinicians. ${ }^{3}$

\section{Imaging}

Chest X-ray (CXR) has been used as a supplementary mode in the diagnosis of pneumonia in children. ${ }^{2}$ However, CXR has major limitations. For instance, it exposes children to ionizing radiation, which may have tardive effects. ${ }^{2-3}$ Moreover, deficiency of abnormalities on CXR does not eliminate the diagnosis, especially in cases when there is a high index of suspicion of clinical pneumonia. ${ }^{3}$ In addition, it has been reported that $\mathrm{CXR}$ is not sensitive in detecting lung consolidations of $\leq 1 \mathrm{~cm}$. ${ }^{4}$ The lack of findings on CXR results in the over diagnosis of bacterial pneumonia and leads to a number of secondary problems, the most important of which is the overuse of unwarranted antibiotics. ${ }^{2}$ Chest computed tomography scan is known to be more accurate than CXR for the diagnosis of pneumonia; however, its use has been discouraged due to high radiation, cost, and perhaps the need for sedation. ${ }^{3}$

\section{Lung ultrasound}

There has been enthusiasm among researchers in developing new devices designed to augment the usefulness and accuracy of the diagnosis of pneumonia, while concurrently reducing exposure to ionizing radiation. Lung ultrasound (LUS) has been 
shortlisted as an option for the diagnosis of pneumonia because it is safe, inexpensive, portable, and uncomplicated to learn and teach. ${ }^{2}$

Several authors studied the sensitivity and specificity of LUS compared to CXR in the diagnosis of pneumonia in children. Pereda et $\mathrm{al}^{3}$ performed a meta-analysis to summarize evidence on the diagnostic accuracy of LUS for childhood pneumonia. A total of 765 children were included in the meta-analysis. The authors concluded that LUS had a sensitivity of $96 \%$ (95\% confidence interval [CI], 94\%-97\%) and specificity of $93 \%(95 \%$ CI, 90\%-96\%) in accurately diagnosing pneumonia in children. In addition, the positive and negative likelihood ratios (LRs) were 15.3 (95\% CI, 6.6-35.3) and 0.06 (95\% CI, 0.03-0.11), respectively. Copetti et $\mathrm{al}^{5}$ compared the diagnostic accuracy of LUS and CXR in children with suspected pneumonia. The study included 79 children with clinical pneumonia, who were subjected to both LUS and CXR. The results of the study showed that CXR was positive for the diagnosis of pneumonia in 53 patients, while LUS was positive in 60. Computed tomography of the chest verified the diagnosis of pneumonia in four patients with positive LUS and negative CXR. In a prospective study, Esposito et $\mathrm{al}^{2}$ compared the sensitivity, specificity, and positive and negative predictive values of LUS with CXR in the diagnosis of pneumonia in children. The study, which included 103 children, concluded that the sensitivity, specificity, and positive and negative predictive values of LUS in comparison to CXR were 97.9\%, 94.5\%, $94.0 \%$, and $98.1 \%$, respectively. In addition, LUS showed higher caliber in the diagnosis of pleural effusion. Shah et $\mathrm{al}^{4}$ conducted a prospective observational cohort study to assess the accuracy of point-of-care LUS for the diagnosis of pneumonia in 200 children and young adults up to 21 years of age. The authors calculated the specificity and positive LR to detail for lung consolidation of $1 \mathrm{~cm}$ or less with ultrasound air bronchograms not seen in CXR. The study concluded that LUS has a specificity of $89 \%(95 \% \mathrm{CI}$, $83 \%-93 \%$ ), sensitivity of $86 \%$ (95\% CI, 71\%-94\%), positive LR of 7.8 (95\% CI, 5.0-12.4), and negative LR of 0.2
Table I Comparison of lung ultrasound with chest radiograph in the diagnosis of pneumonia

\begin{tabular}{lll}
\hline Characteristics & Lung ultrasound & Chest radiograph \\
\hline Portable & Yes & Yes \\
Hazardous & No & Yes \\
Inexpensive & Yes & Yes \\
$\begin{array}{l}\text { Sensitive in diagnosing } \\
\text { consolidations of } \leq \mathrm{I} c \mathrm{~cm}\end{array}$ & Yes & No \\
$\begin{array}{l}\text { Results in overuse of } \\
\text { unwarranted antibiotics }\end{array}$ & No & Yes \\
\hline
\end{tabular}

(95\% CI, 0.1-0.4) for diagnosing pneumonia by visualizing lung consolidation with ultrasound air bronchograms. Table 1 summarizes the advantages of LUS.

\section{Conclusion}

LUS is a safe and accurate mode of imaging that can be used by a health care provider in the cases of suspected pneumonia. It is more sensitive that CXR in the diagnosis of pneumonia and obviates the need for irradiation. Mastering the use of an ultrasound and identifying lung abnormalities lacks complexity, therefore, it is highly recommended that residency programs introduce an intensive short course of radiology as part of the core curriculum.

\section{Disclosure}

The authors report no conflicts of interest in this work.

\section{References}

1. World Health Organization. Pneumonia. Fact Sheet No 331. Geneva, Switzerland. Available from: www.who.int/mediacentre/factsheets/ fs331/en/. Accessed March 22, 2015.

2. Esposito S, Papa SS, Borzani I, et al. Performance of lung ultrasonography in children with community-acquired pneumonia. Ital J Pediatr. 2014; 40:37.

3. Pereda MA, Chavez MA, Hooper-Miele CC, et al. Lung ultrasound for the diagnosis of pneumonia in children: a meta-analysis. Pediatrics. 2015; 135(4):714-722.

4. Shah VP, Tunik MG, Tsung JW. Prospective evaluation of point-of-care ultrasonography for the diagnosis of pneumonia in children and young adults. JAMA Pediatr. 2013;167:119-125.

5. Copetti R, Cattarossi L. Ultrasound diagnosis of pneumonia in children. Radiol Med. 2008;113(2):190-198.
Therapeutics and Clinical Risk Management

\section{Publish your work in this journal}

Therapeutics and Clinical Risk Management is an international, peerreviewed journal of clinical therapeutics and risk management, focusing on concise rapid reporting of clinical studies in all therapeutic areas, outcomes, safety, and programs for the effective, safe, and sustained use of medicines. This journal is indexed on PubMed Central, CAS,

\section{Dovepress}

EMBase, Scopus and the Elsevier Bibliographic databases. The manuscript management system is completely online and includes a very quick and fair peer-review system, which is all easy to use. Visit $\mathrm{http}: / /$ www.dovepress.com/testimonials.php to read real quotes from published authors. 